\title{
New Neutron Log for Small Scale Variations in Carbon/Oxygen Ratio
}

\author{
Vladivoj Valkovic, Davorin Sudac, Karlo Nad, and Jasmina Obhodas
}

\begin{abstract}
The aim of the research reported here is the develop-ment of a methodology for the measurement of small scale varia-tions in chemical elements concentrations, in particular of carbon to oxygen ratio. Knowledge of the $\mathrm{C} / \mathrm{O}$ ratio is of importance to many problems in various fields. Here we single out the application in obtaining important information about the oilfields. The most fundamental reservoir parameters-oil, gas and water content-are critical factors in determining how each oilfield should be devel-oped. It is well established that carbon to oxygen ratio log yields ac-curate and repeatable data that can be used to identify and monitor reserves depletion. Recent improvements in neutron generator and gamma detector technologies resulted in small devices which al-lowed throughtubing measurements. Although the ratio of carbon and oxygen yields is a measure of the amount of oil around the tool it should be realized that a carbon signal can originate from sev-eral sources including the borehole, the cement behind the casing, the formation rock and the formation fluid. In order to evaluate these contributions individually we are proposing the modifica-tion of the neutron generator by insertion of segmented associated alpha particle detector. From the measurement of neutron time of flight spectra (alpha particle detector-start signal; gamma ray de-tector-stop signal) it would be possible to determine the location of gamma-ray production voxel and in such a way to determine ra-dial variations in chemical elements concentrations, in particular of $\mathrm{C} / \mathrm{O}$ ratio.
\end{abstract}

Index Terms - Carbon, carbon/oxygen ratio, gamma ray spectra, neutrons, oil fields, oxygen, small scale variations.

\section{INTRODUCTION}

$\mathbf{T}$ $\mathrm{HE} \mathrm{C} / \mathrm{O}$ ratio is characteristic for many materials and it has been in the center of interest in many research areas.

For example, the carbon-to-oxygen ratio in a planet provides critical information about its primordial origins and subsequent evolution. A primordial $\mathrm{C} / \mathrm{O}$ greater than 0.8 causes a carbide-dominated interior, as opposed to the silicate-dominated composition found on Earth; the atmosphere can also differ from those in the Solar System. The solar $\mathrm{C} / \mathrm{O}$ is 0.54 [1]. Some 500 exoplanets, or planets outside the solar system, have been discovered to date. Until recently, infrared observations of exoplanetary atmospheres have typically been interpreted using models that assumed solar elemental abundances. However,

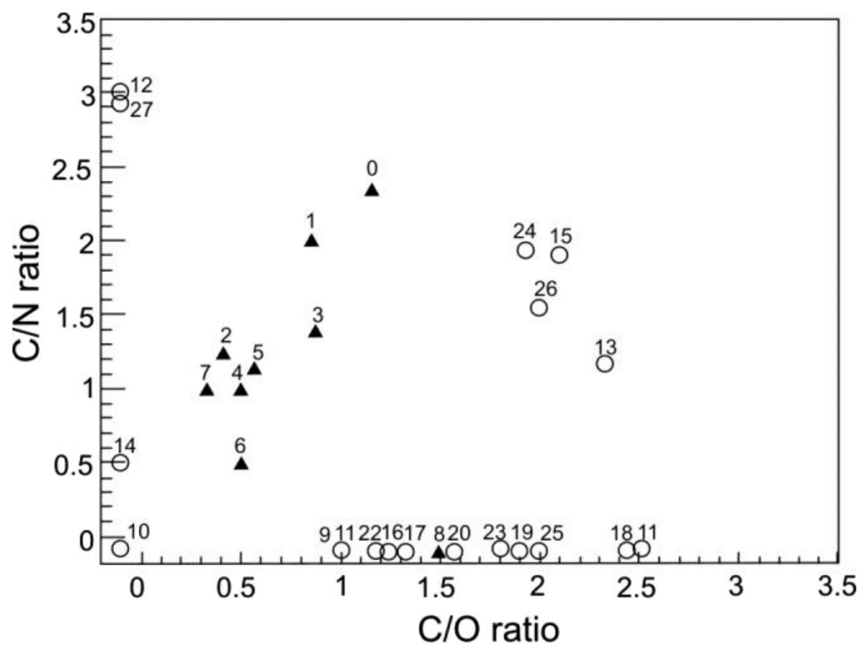

Fig. 1. $\mathrm{C} / \mathrm{N}$ versus $\mathrm{C} / \mathrm{O}$ map showing the position of different materials. Symbolsrepresent 0-TNT, 1-melinite, 2-semtex, 3-tetryl, 4-HNB, 5-heptanitrocubane, 6-RDX, 7-nitroglycerine, 8-acetone peroxyde, 9-glucose, 10-PVC, 11-plexyglass, 12-latex, 13-nylon, 14-melamine, 15-acetamide, 16-barley, 17-cotton, 18-dacron, 19-ethanol, 20-lucite, 21-methanol, 22-paper, 23-wood, 24-wool, 25-PET, 26-silk, 27-orlon.

recent observations have revealed deviations from predictions based on such classification schemes, and chemical compositions retrieved from some data sets have also indicated non-solar abundances, i.e. deviation in $\mathrm{C} / \mathrm{O}$ ratio from 0.5 (solar value).

Organic compounds can be recognised from their formulae - they all contain the element carbon with different $\mathrm{C} / \mathrm{O}$ ratios. The common inorganic compounds that contain carbon are carbon dioxide $\left(\mathrm{CO}_{2}\right)$, carbon monoxide $(\mathrm{CO})$, salts containing the carbonate ion $\left(\mathrm{CO}_{3}^{2-}\right)$ or the hydrogencarbonate ion $\left(\mathrm{HCO}_{3}^{-}\right)$and inorganic carbonyl compounds e.g. $\mathrm{Co}(\mathrm{CO})_{6}$.

Fig. 1 shows $\mathrm{C} / \mathrm{N}$ versus $\mathrm{C} / \mathrm{O}$ map showing the measured values for different materials. Explosives and other materials are represented by triangles and circles, respectively. Substances having no nitrogen or no oxygen have been placed on the x-axis and on the y-axis, respectively.

Coal researchers have known for many years that the weight percent ratio of carbon to oxygen in coal increases with progressive metamorphism of coal. The $\mathrm{C} / \mathrm{O}$ ratio in coal increases linearly between the ranks of lignite $(\mathrm{C} / \mathrm{O} \sim 2.1)$ and medium volatile bituminous $(\mathrm{C} / \mathrm{O} \sim 12-14)$. Fig. 2 shows carbon versus oxygen content (dry, ash-free basis) of about 1,200 coals ranging in rank from lignite to anthracite. Field of data points is enclosed by the dashed lines; approximate regression curve shown by the solid line. Approximate equation for assumed 


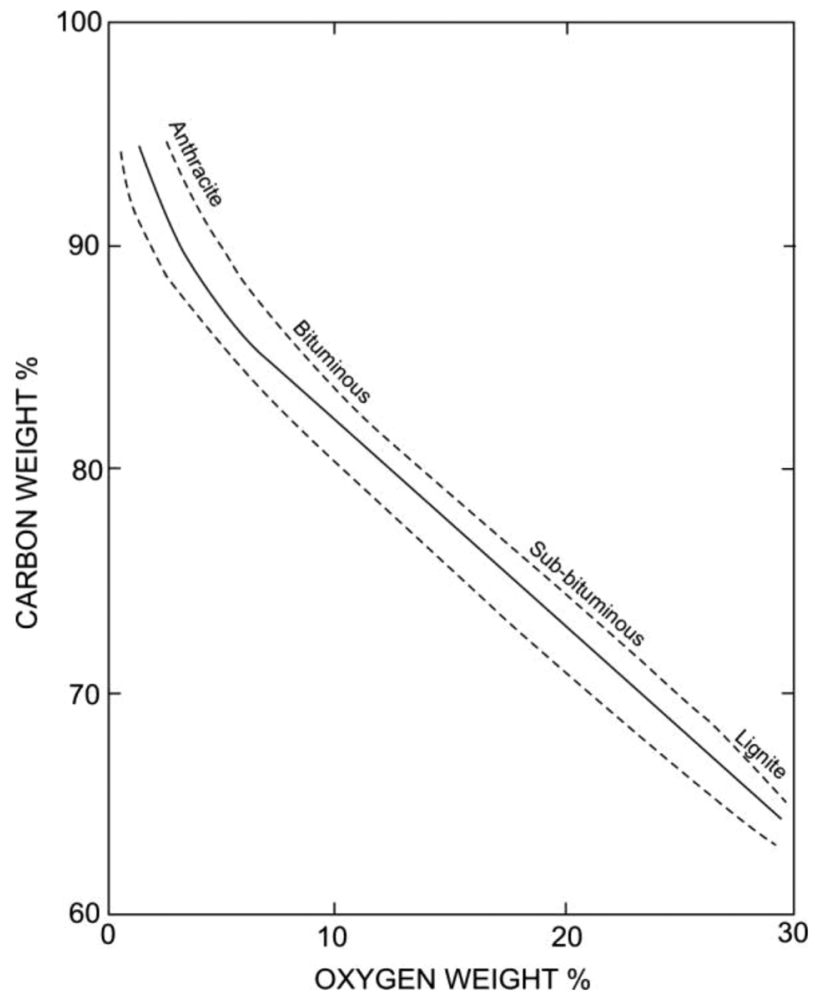

Fig. 2. Carbon to oxygen ratio for different coal samples [2].

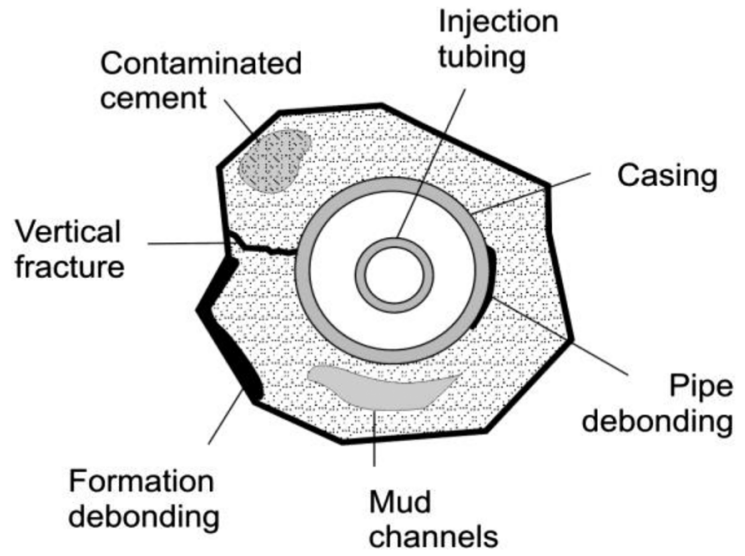

Fig. 3. Typical injection well schematic-view from above.

linear regression curve between carbon values of 65 and 85 percent: $y=-0.92 \mathrm{x}+91.5$ (after ref. 2). This relation was first introduced by Hickling in 1931 [3]. The fact that the $\mathrm{C} / \mathrm{O}$ ratio is an indicator of coal rank suggests its use in an area where the coal varies significantly in rank.

The most fundamental reservoir parameters-oil, gas and water content-are critical factors in determining how each oilfield should be developed. It is well established that carbon to oxygen ratio $\log$ yields accurate and repeatable data that can be used to identify and monitor reserves depletion. Typical injection well schematic-view from above, following Rowe [4] is shown in Fig. 3.

Different methods and tools are used to obtain information from the well logging activities. The parameters of interest are depth of investigation and resolution of logging tools, where the depth is a distance from the inner tubing. The resistivity logging tool has depth of investigation $160 \mathrm{~cm}$ (laterolog) to $260 \mathrm{~cm}$ (induction $\log$ ) and resolution of $80 \mathrm{~cm}$ in both cases. Within nuclear loging one should differentiate between neutron $\log$, gamma-ray log and density log; the depth of investigation and resolution of logging tools being $70 \mathrm{~cm}$ and $40 \mathrm{~cm}, 55 \mathrm{~cm}$ and $30 \mathrm{~cm}, 40 \mathrm{~cm}$ and $20 \mathrm{~cm}$, respectively. Sonic digital tool has depth of only $10 \mathrm{~cm}$ and resolution of some $60 \mathrm{~cm}$. Micro resistivity logging tool can have depth of $10 \mathrm{~cm}$ and resolution of $5 \mathrm{~cm}$; while dipmeter depth and resolution are of the order of $2 \mathrm{~cm}$.

The evaluation of cement integrity is done with an ultrasonic transducer $(0.2-0.7 \mathrm{MHz})$ using resonance technique to locate and give information on casing weld, gas microannulus, mud channels, perforations, well centered casing washouts and eccentered casing.

Nuclear well logging is a well-established method of studying the materials surrounding exploratory boreholes. A tool consisting of a neutron or gamma-ray source and one or more detectors is lowered into the borehole. The response of the detectors to radiation returning from outside the borehole depends in part on the lithology, porosity, and fluid characteristics of the material. In principle, the characteristics of the materials outside the borehole can be inferred from the response of the detectors. The elements of interest for inelastic gate of the inelastic mode are $\mathrm{C}, \mathrm{O}, \mathrm{Si}, \mathrm{Ca}, \mathrm{S}$ and $\mathrm{Fe}$. The yields from elements $\mathrm{H}, \mathrm{Si}, \mathrm{Ca}, \mathrm{Cl}$, $\mathrm{Fe}$ and $\mathrm{S}$ are obtained in the capture mode and from capture gate of the inelastic mode.

Carbon-oxygen $\log$ is a $\log$ which presents a measure of the relative abundance of $\mathrm{C}$ to $\mathrm{O}$ derived from the detection of the gamma rays produced from both elements by the inelastic scattering of 14-MeV neutrons. The gamma rays are measured within energy spectrum windows representing the gamma-ray escape peaks of $\mathrm{C}$ and $\mathrm{O}$. The ratio of counting rates provides a means of predicting the relative amounts of hydrocarbons and water. The $\log$ is an alternate means for detecting hydrocarbons (particularly oil) behind casing in formations not subject to flushing or reinvasion by borehole fluids. The $\mathrm{C} / \mathrm{O}$ ratio is relatively independent of formation water salinity and shaliness. In order to differentiate carbon in hydrocarbon molecules from that in the rock framework (i.e., carbonate solid matter), a Si/C ratio is also determined.

The carbon-to-oxygen ratio contains valuable information concerning the location of oil and/or gas bearing rock. These inelastic elemental yields have been studied for years to measure oil saturation by determining a carbon-to-oxygen ratio [5]-[8]. Carbon-oxygen logging is used primarily to estimate oil saturation in cased-hole conditions when the formation water is fresh or of unknown salinity.

The carbon to oxygen ratio model is based on the fact that the ratio of $\mathrm{C}$ and $\mathrm{O}$ yields is a measure of the ammount of oil around the tool. This ratio is depending on many variables including oil saturation, borehole oil fraction, porosity, lithology, borehole diameter, casing diameter casing weight.

Although the ratio of carbon and oxygen yields is a measure of the amount of oil around the tool it should be realized that a carbon signal can originate from several sources including the borehole, the cement behind the casing, the formation rock and 


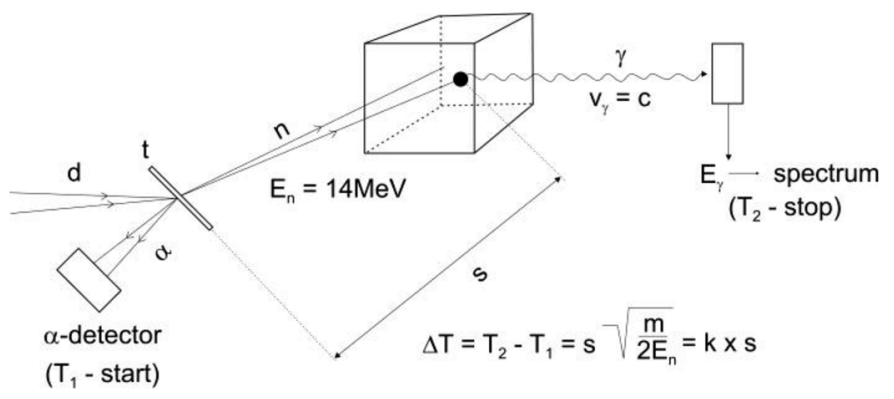

Fig. 4. The physical principle of material inspection by tagged neutron beam.

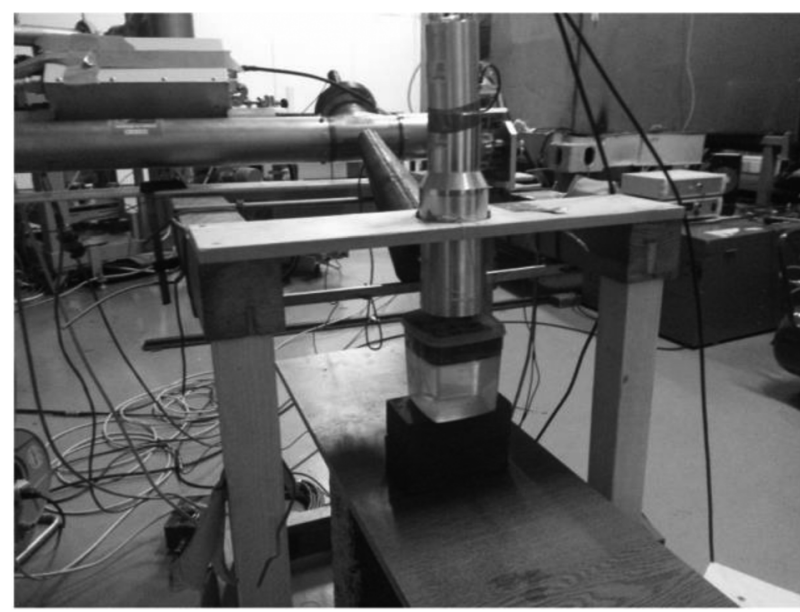

Fig. 5. Experimental setup with API-120 neutron generator.

the formation fluid. In order to evaluate these contributions individually we are proposing the modification of the neutron generator by insertion of segmented associated alpha particle detector. From the measurement of time of flight spectra (alpha particle detector-start signal; gamma ray detector-stop signal) it will be possible to determine the location of gamma ray producing voxel and in such a way to determine radial variations in carbon to oxygen ratio.

\section{Sensor With TagGed Neutron Beam}

Recent developments in technology of neutron generator manufacturing have enabled the application of fast neutron activation analysis to variety of problems. The major breakthrough has been accomplished by using the detection of associated alpha particles in the neutron producing reaction $\mathrm{d}+\mathrm{t} \rightarrow \alpha$ $+n$. The cone of detected $\alpha$-particles defines the cone of neutrons, "neutron beam", and if the neutron produced $\gamma$-rays are detected in coincidence with $\alpha$-particles the volume where they are produced is defined by overlap of "neutron beam" cone and $\gamma$-detector solid angle. Measurement of time between these two events gives the information on distance of investigated voxel from the neutron source (see Fig. 4).

The basic components of such a system are shown in Fig. 5 where the source of tagged neutron beam is Thermo Scientific API-120 neutron generator with the cone of shielding material protecting gamma detector from direct irradiation and with an oil-in-water target being measured.

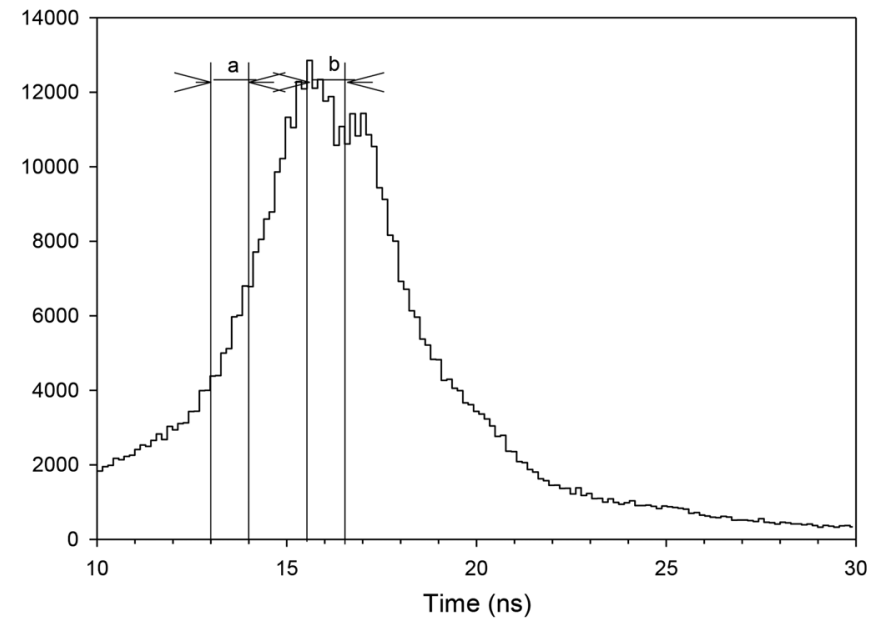

Fig. 6. Time spectrum from bombardment of oil in water target using API-120 neutron generator and $\mathrm{LaBr}_{3}(\mathrm{Ce})$ detector.

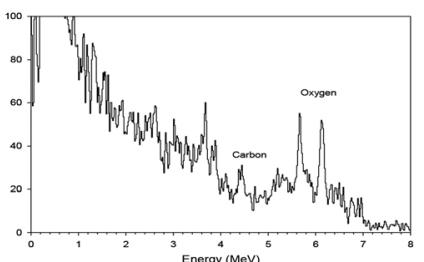

(a)

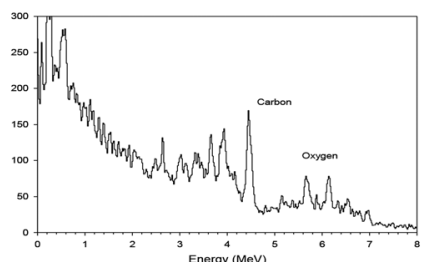

(b)
Fig. 7. Gamma-ray spectrum from time window "a" (left) corresponding to the water portion and time window "b" (right) in the time spectrum corresponding to diesel portion.

As an example, the measured $\alpha-\gamma$ time spectrum is shown in Fig. 6 resulting from the neutron bombardment of oil in water target. The time spectrum was obtained by signals from YAP $(\mathrm{Ce})$ alpha detector inside API-120 neutron generator and from $\mathrm{LaBr}_{3}(\mathrm{Ce})$ gamma detector. Windows on the regions of the spectrum marked "a" and " $b$ " were applied when analysing the gamma-ray energy spectrum. This procedure results in two quite different energy spectra as shown in Fig. 7.

In the previous works [9] accent was based on determination of empirical non-hydrogen part of chemical formula of explosives, drugs, threat materials: $\mathrm{C}_{\mathrm{x}} \mathrm{N}_{\mathrm{y}} \mathrm{O}_{\mathrm{z}}$ from fast neutron induced gamma emission. Approach described here is based on using the value of $\mathrm{C} / \mathrm{O}$ ratio only. There is no need here for the questionable determination of nitrogen concentration. However, it is important that the experimental parameters are chosen in such a way as to insure that the value of $\mathrm{C} / \mathrm{O}$ ratio is representative of the material inside the interrogated object. The neutron sensor needs to operate inside the oil well casing pipes. The wall thickness of oil well casing pipes depends on their size, weight and outside diameter $(168-508 \mathrm{~cm})$ and it is in the $5.9-16.1 \mathrm{~mm}$ range.

The casing tube walls are of thickness which should not represent an obstacle to such approach. The knowledge of iron shell thickness is mandatory for correct investigated material inside the container for the $\mathrm{C} / \mathrm{O}$ concentration ratio determination from the measured gamma spectrum. This information could be obtained from the (i) knowledge of construction details of investigated object and precise position of the neutron system, 


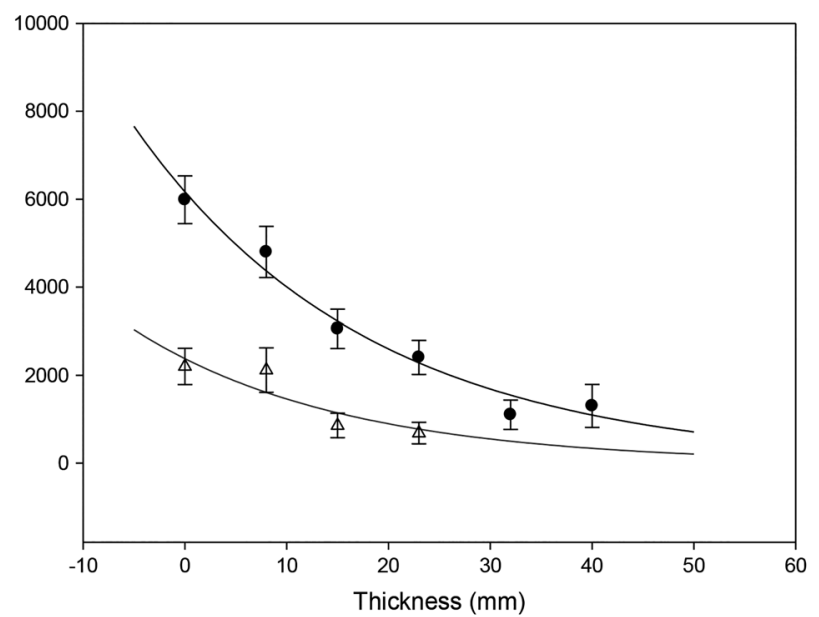

Fig. 8. The experimental data on the attenuation of gamma ray intensity in the iron. Upper line: the number of counts in carbon $4.44 \mathrm{MeV}$ peak. Lower line: $5.62 \mathrm{MeV}$ escape peak of oxygen $6.13 \mathrm{MeV}$ peak.

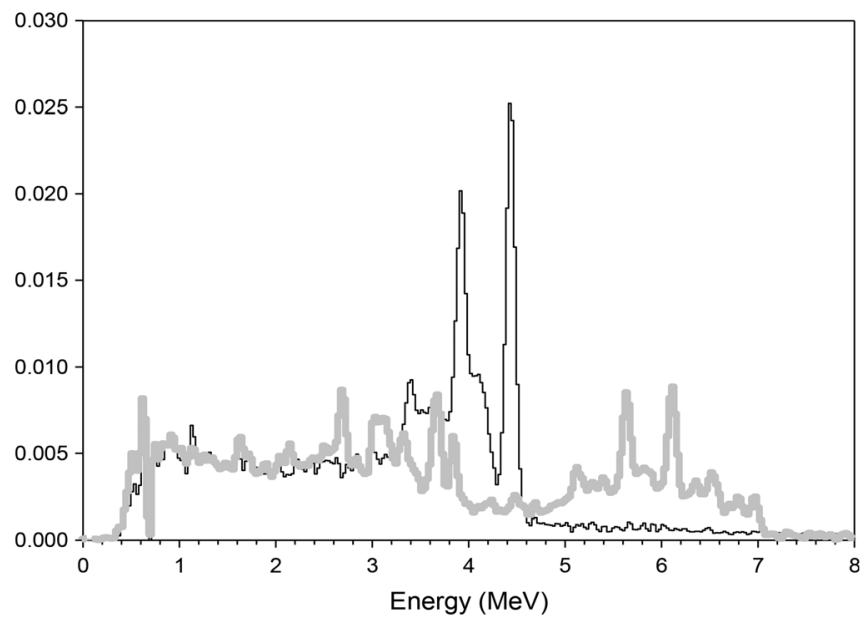

Fig. 9. Normalized gamma-ray spectra from carbon (black) and water (gray) targets. Detector is $\mathrm{LaBr}_{3}(\mathrm{Ce})$.

and/or (ii) from the iron peak in the measured gamma spectrum. Fig. 8 shows the number of counts in carbon $4.44 \mathrm{MeV}$ peak (upper) and oxygen $5.62 \mathrm{MeV}$ peak being the first escape peak of oxygen $6.13 \mathrm{MeV}$ line (lower) as a function of iron plate thickness.

In order to apply this approach, gamma spectra of oxygen and carbon need to be measured in the environment in which the investigated object is located. Fig. 9 and Fig. 10 show normalized gamma ray spectra from carbon (black) and water (gray) gamma detectors being $\mathrm{LaBr}_{3}(\mathrm{Ce})$ and $\mathrm{BGO}$, respectively.

Often $\mathrm{C} / \mathrm{O}$ ratio needs to be determined for the identification of investigated object. In the measurements reported here iron cylinders $(\Phi 15.5 \mathrm{~cm} \times 60 \mathrm{~cm}$, wall $1 \mathrm{~cm})$ were filled with mixture of graphite and $\mathrm{SiO}_{2}$ sand in order to obtain known $\mathrm{O} / \mathrm{C}$ ratios. These cylinders were then placed in an iron pool and irradiated with and without water in it at various distances. Fig. 11 shows determination of $\mathrm{C} / \mathrm{O}$ ratio in the air. Fig. 12 shows the $\mathrm{C} / \mathrm{O}$ ratio measured in water which depends on the calculated (real) $\mathrm{C} / \mathrm{O}$ and on the distance which tagged neutrons must travel to the target through the water. By knowing

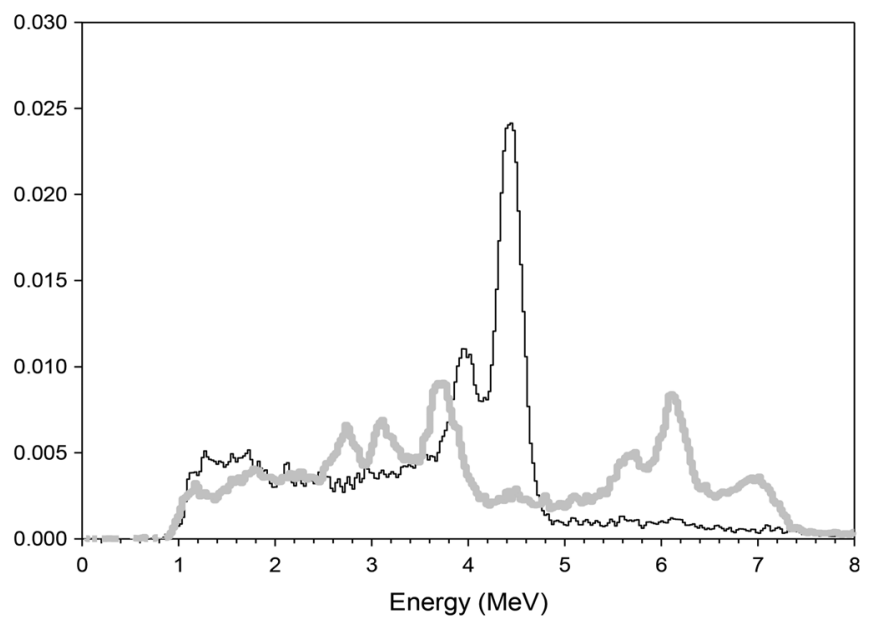

Fig. 10. Normalized gamma- ray spectra from carbon (black) and water (gray) targets. Detector is BGO.

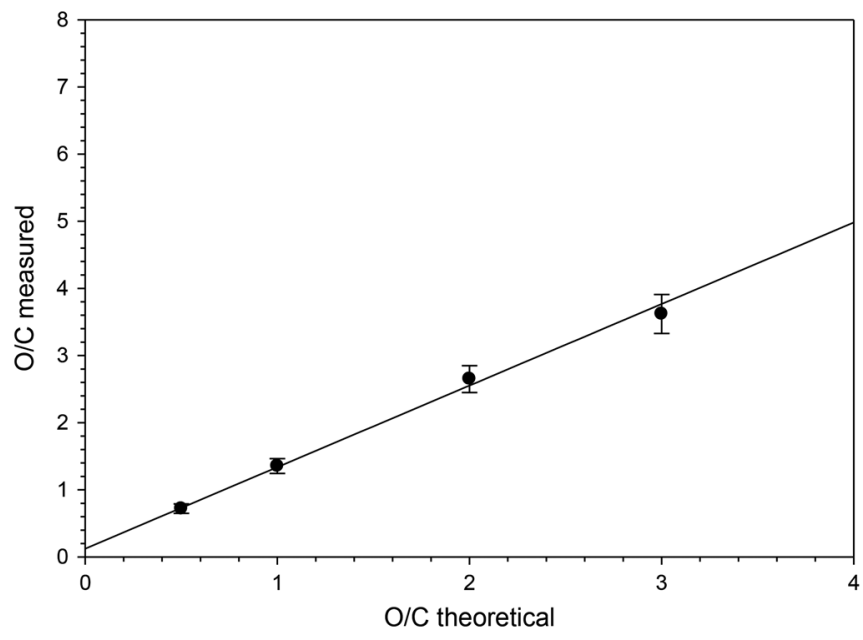

Fig. 11. Measurement in the air. $\mathrm{O} / \mathrm{C}$ measured $=(0.123 \pm 0.05)+$ $(1.215 \pm 0.05)^{*} \mathrm{O} / \mathrm{C}$ theoretical.

the functional dependence it is possible to find the real $\mathrm{C} / \mathrm{O}$ if the distance to the object is known with the precision less than $1 \mathrm{~cm}$. Functional dependence could be found by using the calibration procedure described above. The $\mathrm{C} / \mathrm{O}$ measured in the water also depends on the object shape and dimensions and on the iron (or other material) shell thickness.

\section{Preliminary Measurements}

Here we present the preliminary results of the $\mathrm{C} / \mathrm{O}$ ratio measurements obtained by the laboratory size setup. The experimental setup with two plastic containers with $50 \%$ water $-50 \%$ diesel fuel at distances $12 \mathrm{~cm}$ and $24 \mathrm{~cm}$ from the gamma detector is shown in Fig. 13.

Neutrons are produced by the VNIIA (Russia) ING-27 neutron generator equiped with $3 \times 3$ segmented alpha detector producing in such a way 9 electronically collimated neutron beams as shown in Fig 14.

In order to demonstrate the localization capabilities of the setup two alpha particle detector pixels are used in evaluation of t-o-f spectra. Gamma-ray spectrum resulting from the window on time-of-flight (t-o-f) spectrum from central pixel of alpha 


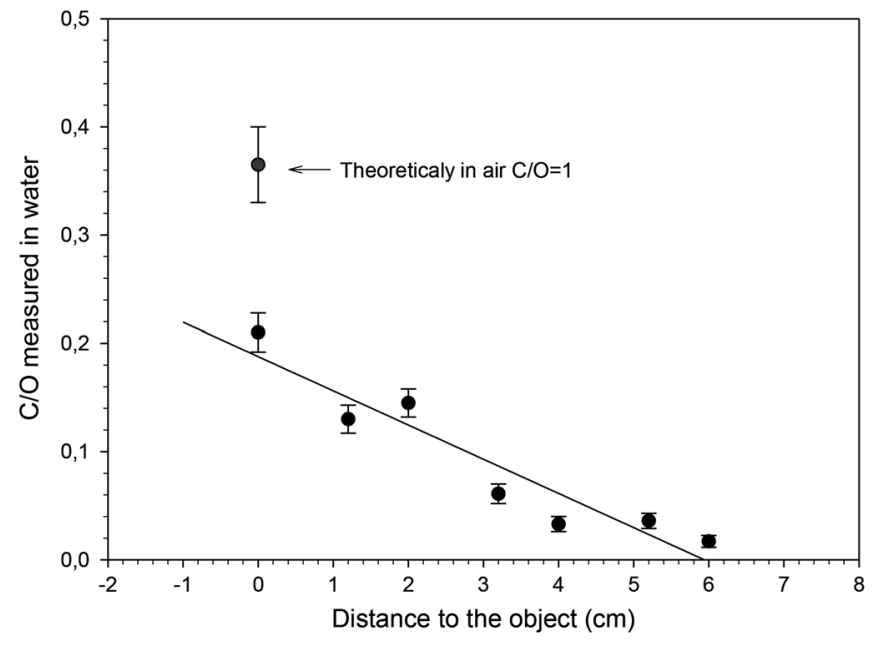

Fig. 12. $\mathrm{C} / \mathrm{O}$ ratio measured in water.

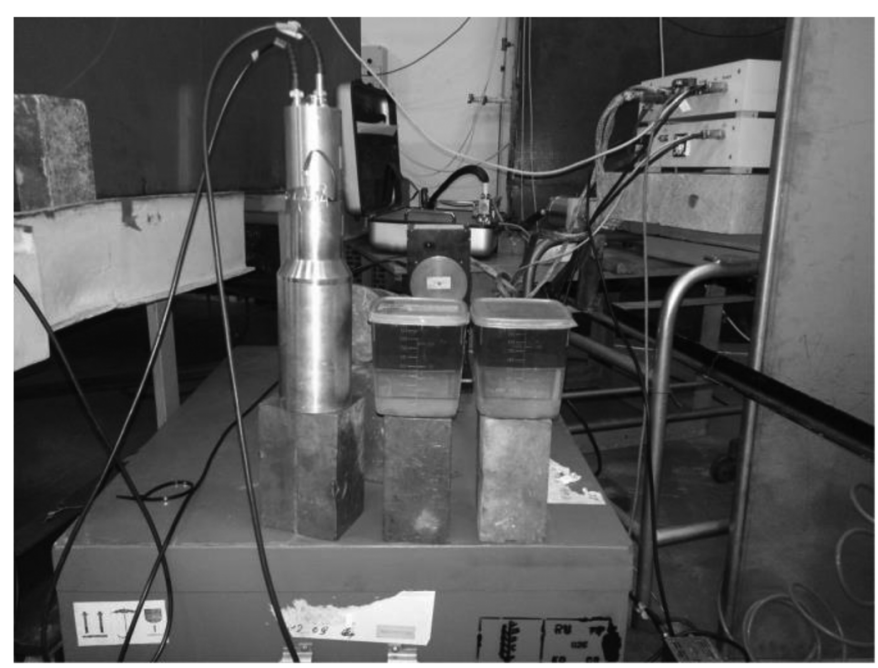

Fig. 13. Experimental setup-neutron generator: ING-27 with $4 \pi$ intensity $3 \times$ $10^{7} \mathrm{n} / \mathrm{s}$, associated alpha particle method with $3 \times 3$ segmented detector; gamma detector: $3^{\prime \prime} \times 3^{\prime \prime} \mathrm{LaBr}_{3}$ : Ce; target: $50 \%$ water- $50 \%$ diesel fuel mixture in 1 litter plastic containers.

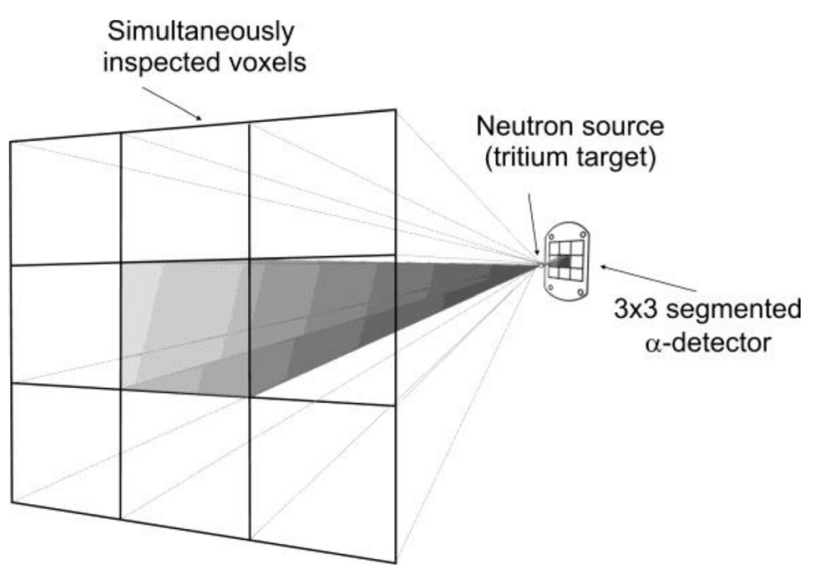

Fig. 14. The nine electronically collimated neutron beams.

particle detector is shown in Fig. 15 corresponding to the target container at $\mathrm{d}=12 \mathrm{~cm}$ from the gamma detector. Gamma ray spectrum resulting from the window on t-o-f spectrum from the

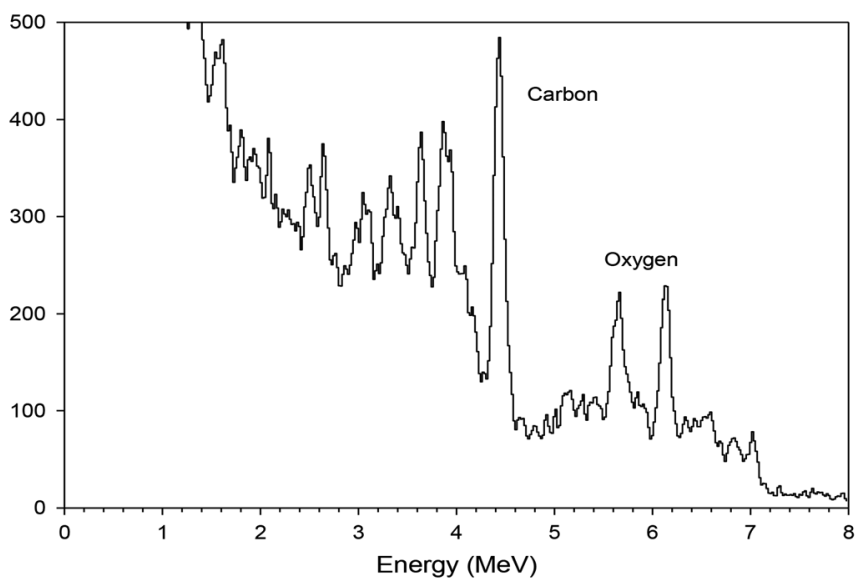

Fig. 15. Gamma-ray spectrum for $50 \%$ volume of diesel fuel and $50 \%$ of water in the 1 litter target container at $\mathrm{d}=12 \mathrm{~cm}$ from gamma detector.

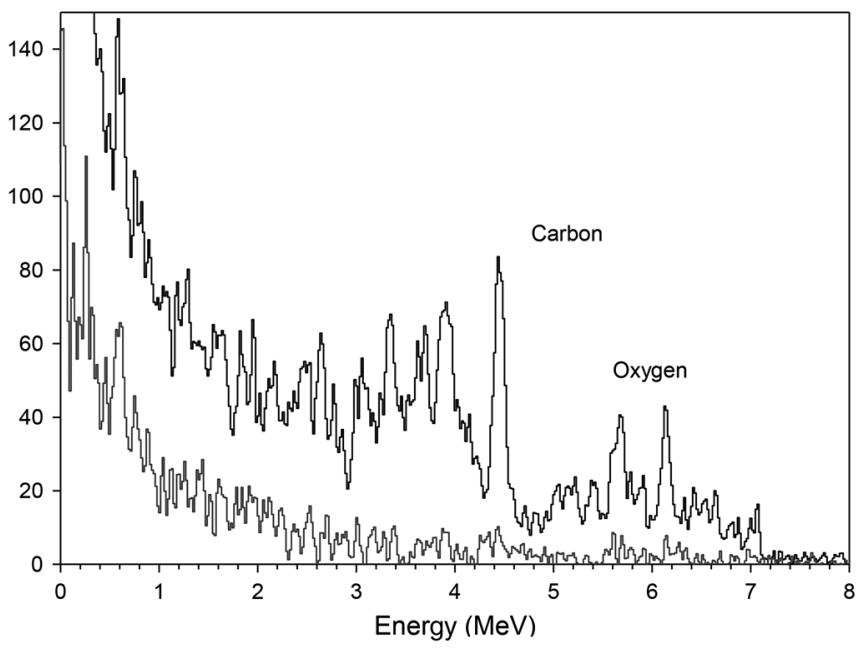

Fig. 16. Gamma ray spectrum for $50 \%$ volume of diesel fuel and $50 \%$ of water in the 1 litter target container at $\mathrm{d}=24 \mathrm{~cm}$ from gamma detector. Lower spectrum is obtained with target out measurement.

adjancent pixel of alpha particle detector is shown in Fig. 16 corresponding to the target container at $\mathrm{d}=24 \mathrm{~cm}$ from the gamma detector (the one on the right in Fig. 13). Measured spectra are dominated by $\mathrm{O}$ and $\mathrm{C}$ peaks with their ratio varying according to proportion of diesel fuel in the target volume, while the intensities of the peaks decrease with the distance.

Fig. 17 shows the variation of $\mathrm{C} 4.44 \mathrm{MeV}$ peak intensity for different fractions of diesel fuel while Fig. 18 shows the same for the $\mathrm{O} 6.13 \mathrm{MeV}$ peak.

Finaly, from these measured data one can obtain calibration curve for the $\mathrm{C} / \mathrm{O}$ concentration ratios as shown in Fig. 19.

The same type of information will be possible to obtain from the use of proposed new generator when used in logging operations. The small scale $(\leq 10 \mathrm{~cm})$ variations of the relative elemental abundances, most interesting being $\mathrm{C} / \mathrm{O}$ ratio, could be obtained in the interesting regions of the well.

By the use of tagged $14 \mathrm{MeV}$ neutrons one could also determine the depth variation of the stoichiometric ratios for other chemical elements of interest: $\mathrm{Ca}, \mathrm{Si}, \mathrm{Al}, \mathrm{Fe}, \mathrm{O}$ (cement constituents) and $\mathrm{C}$ introduced by additives and/or during cement 


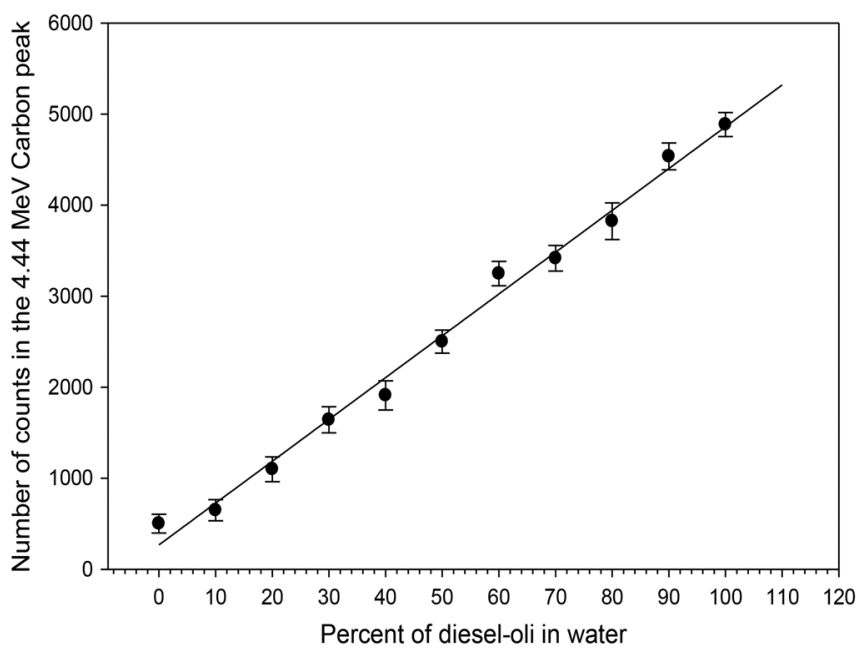

Fig. 17. Number of counts in carbon peak, experimental points, as a function of diesel fuel volume percentage in the water mixture, linear fit.

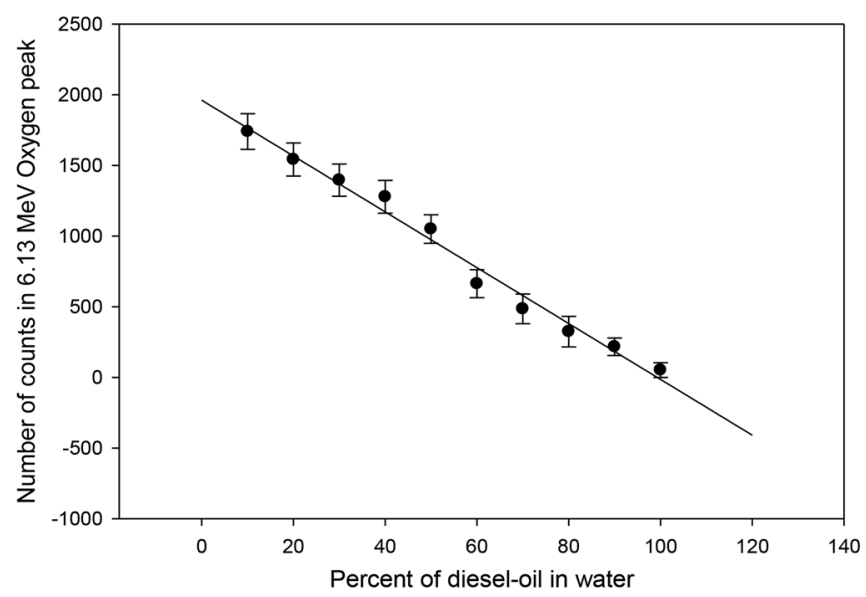

Fig. 18. Number of counts in oxygen peak, experimental points, as a function of diesel fuel volume percentage in the water mixture, linear fit.

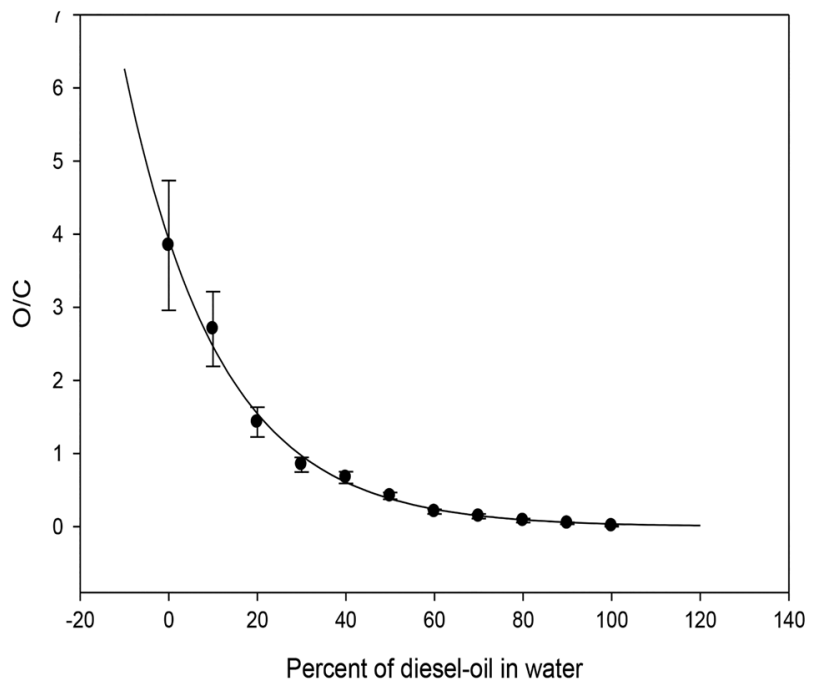

Fig. 19. Experimentaly determined $\mathrm{O} / \mathrm{C}$ ratio as a function of diesel fuel volume percentage in the water mixture with exponential fit to data points.

curing process (see Fig. 20 for gamma spectra obtained by irradiation of cement).

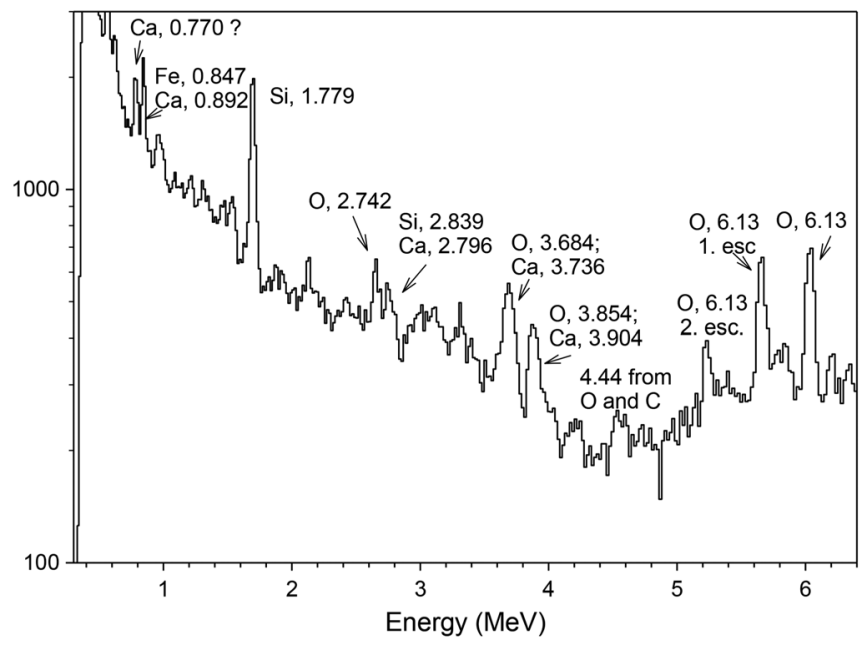

Fig. 20. Gamma energy spectrum resulting from $14 \mathrm{MeV}$ irradiation of concrete block of mass $18.75 \mathrm{~kg}$ (3.6 kg Portland cement, $1.65 \mathrm{~kg}$ water, $4.5 \mathrm{~kg}$ gravel, $9 \mathrm{~kg}$ quartz sand).

\section{New C/O Log And Future Tests}

The aim of the proposed research is to develop a methodology for the measurement of small scale variations in $\mathrm{C} / \mathrm{O}$ ratio $\log$. Carbon to oxygen ratio log yields accurate and repeatable data that can be used to identify and monitor reserves depletion. As already mentioned, carbon signal can originate from several sources including the borehole, the cement behind the casing, the formation rock and the formation fluid [8].

$\mathrm{C} / \mathrm{O}=\mathrm{A}\left(\mathrm{C}_{\mathrm{M}}+\mathrm{C}_{\mathrm{PS}}+\mathrm{C}_{\mathrm{BH}}+\ldots ..\right) /\left(\mathrm{O}_{\mathrm{M}}+\mathrm{O}_{\mathrm{PS}}+\mathrm{O}_{\mathrm{BH}}+\ldots \ldots ..\right)$

Where $\mathrm{A}$ is a constant reflecting diferences in inelastic neutron cross section for $\mathrm{O}$ and $\mathrm{C}$; with only matrix, $\mathrm{M}$, pore space, PS and borehole, $\mathrm{BH}$ sources being specified.

In order to evaluate these contributions individually we are proposing the modification of the neutron generator by insertion of segmented associated alpha particle detector. From the measurement of time of flight spectra it will be possible to determine the location of gamma ray producing voxel and in such a way to determine radial variations in carbon to oxygen ratio.

Schematic presentation of the production and use of the neutron beam "collimated" by the detection of the associated alpha particles is shown in Fig. 4[10], [11]. For the preliminary research we propose the use of the focused $100 \mathrm{keV}$ deuteron beam from the Cockcroft-Walton accelerator of the Institute Ruder Boskovic to test the neutron production, associated alpha detection and gamma detection components of the new nuclear $\log$ housed in the $4.3 \mathrm{~cm}$ diameter housing. The schematic drawing of the proposed new nuclear log is shown in Fig. 21 and Fig. 22 The information on $\mathrm{C} / \mathrm{O}$ ratio spatial variations will be measured for variable material characteristics and experimental geometries.

Associated alpha particle detector will be composed of the annular 4-segmented $\mathrm{YAP}(\mathrm{Ce})$ scintillator (outer diameter $=37.5 \mathrm{~mm}$, inner diameter $=7.5 \mathrm{~mm}$, thickness $0.5 \mathrm{~mm}$ ), input side of the scintillator coated with Ag; 4 independent quartz glass light guides covered by Al layer which 


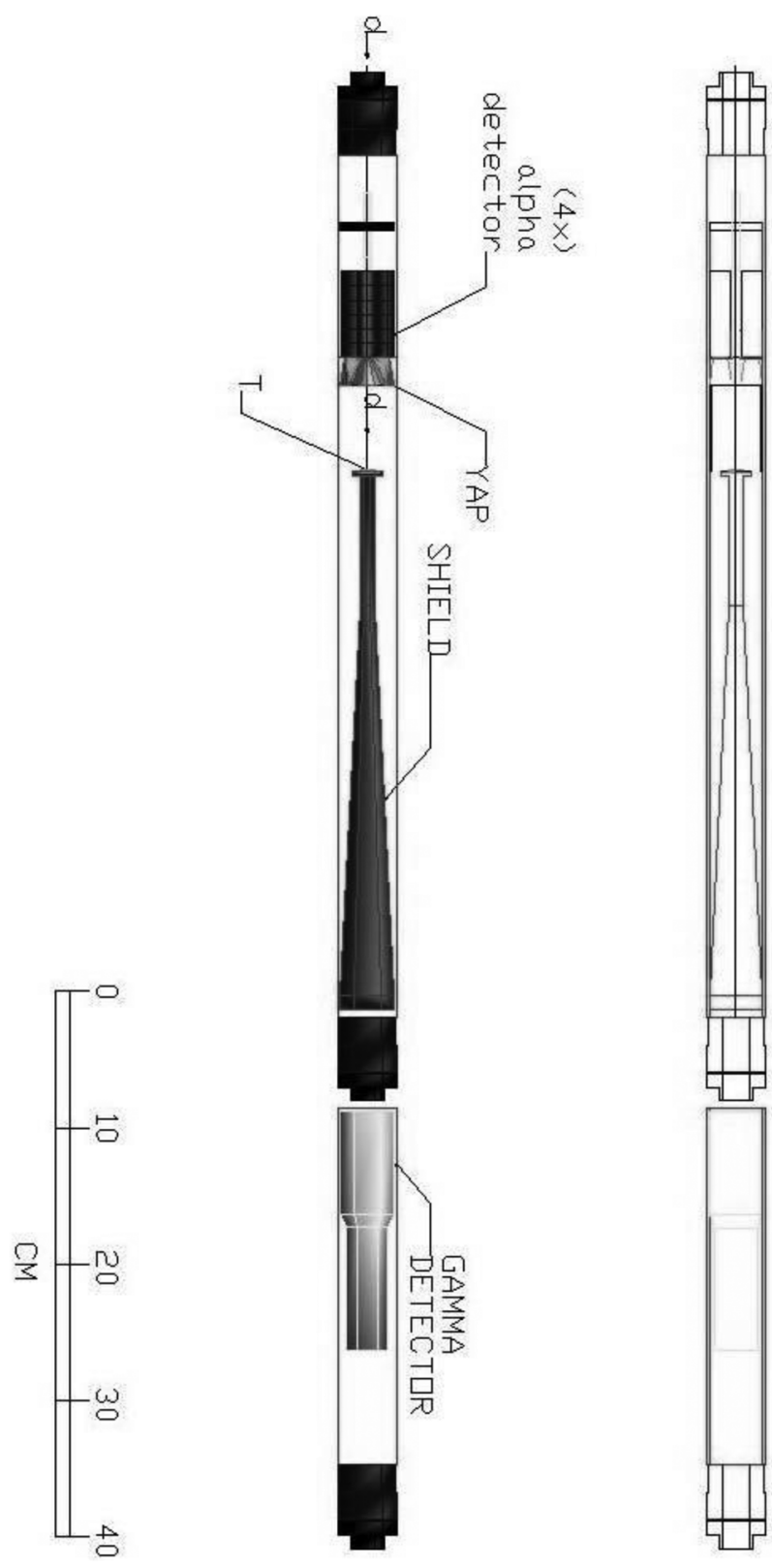

Fig. 21. A view of the proposed alpha and gamma detection system.

are light tightly separated, light guides are polished on all sides; $4 \times$ PMT Hamamatsu R4177 with divider mechanically connected to the light guide with mu-metal schielding of PMT; $4 \times \mathrm{HV}$ and $4 \times$ signal connector with everything encapsulated in stainless steel housing. Accelerator produced $100 \mathrm{keV}$ deuteron beam will pass through central tube and hit the tritium target.

The shielding material behind the tritium target will prevent produced neutrons to hit gamma detector and produce noise. Gamma detector, most probably BGO or $\mathrm{NaI}(\mathrm{Tl})$ crystal, (to be determined during the test period) will be followed by a photomultiplier tube. Two parameters will be measured: alphagamma t-o-f spectrum and gamma energy spectra. With t-o-f resolution of $2 \mathrm{~ns}$ approximately $10 \mathrm{~cm}$ voxels could be measured for relative elemental abundances, most interesting being $\mathrm{C} / \mathrm{O}$ ratio.

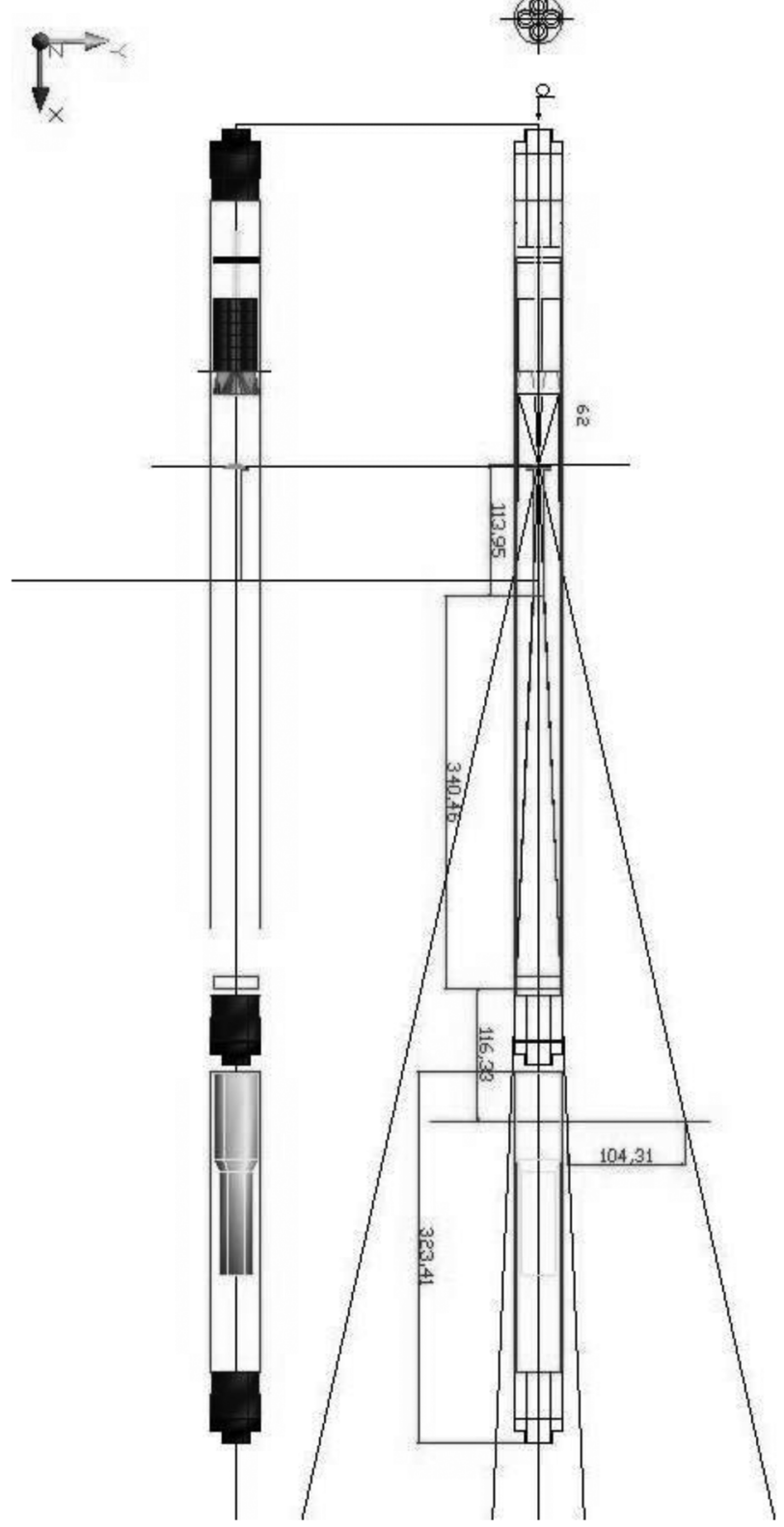

Fig. 22. Another view of the alpha-gamma system. Both, associated alpha particle cone and tagged neutron cone, on the opposite side of tritium target, are shown.

\section{CONCLUSION}

By acquiring the inelastic gamma-ray and time-of-flight spectra, the $\mathrm{C}$ and $\mathrm{O}$ concentration ratios could be obtained to determine small scale variations in oil saturation and borehole oil fraction. Information on small scale variations in lithology, porosity and salinity can also be obtained. Logging is proposed to be performed as stationary measurements in this mode, but for higher porosities, low speed $(\leq 20 \mathrm{~m} / \mathrm{hr})$ continuous passes will be tested.

A carbon signal can originate from the borehole, the cement behind the casing, the formation rock and the formation fluid. In the proposed approach, the fraction of the carbon-oxygen ratio, being a measure of the amount of oil around the tool, will be spatially characterized. 
Measurements of $\mathrm{C} / \mathrm{O} \log$ are not performed at present on many oil fields around the world. They are must if one wants to avoid incomplete exploration of oil reserves in the particular field. Financial benefit for the countries and companies involved could be not only in the confirmation of the increase in oil reserves, but also in benefits resulting from the introduction of new technique for well characterization.

\section{REFERENCES}

[1] M. Asplund, N. Grevesse, and A. Sauval, "Cosmic abundances as records of stellar evolution and nucleosynthesis," in Proc. ASP Conf., T. G. Barnes, III and F. N. Bash, Eds., 2005, pp. 25-38, Ser. 336.

[2] J. R. Dyni and D. L. Gaskill, "Relation of the carbon/oxygen ratio in coal to igneous intrusions in the somersewt coal field, colorado," Contribut. Geochem., Geo. Survey Bull., vol. 1477-A, pp. A1-A20, 1980.

[3] H. G. A. Hickling, "The geological history of coal," Fuel Sci. Prac., vol. 10, pp. 212-232, 1931, 1931
[4] W. Rowe, "Well monitoring and logging," Apr. 18, 2012 [Online]. Available: http://www.slb.com/carbonservices

[5] W. E. Schultz and H. D. Smith, "Laboratory and field evaluation of carbon/oxygen well logging system,” J. Petrol. Technol., pp. 1103-10, 1974.

[6] G. A. Lock and W. A. Hoyer, "Carbon-oxygen (C/O) log: Use and interpretation," J. Petrol. Technol., pp. 463-70, 1974.

[7] B. A. Roscoe and J. A. Grau, "Response of the carbon/oxygen measurement for an inelastic gamma ray spectroscopy tool," SPE Form. Eval., Mar. 76-80, 1988.

[8] B. A. Roscoe et al., "A new through tubing oil saturation measurement system," in Proc. SPE Middle East Oil Show, Bahrain, Nov. 1991, pp. $16-19$.

[9] B. Perot et al., "The EURITRACK project: Development of a tagged neutron inspection system for cargo containers," Proc. SPIE, vol. 6213, pp. 621302-1-6, 2006.

[10] V. Valkovic et al., "The use of alpha particle tagged neutrons for the inspection of objects on the sea floor for the presence of explosives," Nucl. Instrum. Methods Phys. Res. A, vol. 703, pp. 133-137, 2013.

[11] D. Sudac, K. Nad, J. Obhodas, and V. Valkovic, "Monitoring of underwater concrete structures by using the $14 \mathrm{MeV}$ tagged neutron beams," Radiat. Meas., 10.1016/j.radmeas.2013.06.001, to be published. 